\title{
¿POR QUÉ GRITA ESA MUJER? TRES PROPUESTAS POÉTICAS PARA UNA SUBJETIVIDAD DIFERENCIADA*
}

\author{
¿POR QUÉ GRITA ESA MUJER? THREE POETICS PROPOSALS \\ FOR A DIFFERENTIATED SUBJECTIVITY
}

Biviana Hernández O.

Pontificia Universidad Católica de Chile. Santiago, Chile biviana.hernandezz@gmail.com

\begin{abstract}
Resumen: En este artículo propongo una lectura de tres textos fundamentales del corpus poético femenino de los 80-90 latinoamericanos: Naciste pintada (Carmen Berenguer, 1999), Noches de adrenalina (Carmen Ollé, 1981), y Ova completa (Susana Thénon, 1987). Parto de la hipótesis de una subjetividad diferenciada por la marca de género -escritura "de mujeres" o escritura "feminizada" - y una ética-política de lo íntimo y cotidiano, según registros que incluyen desde la cita vanguardista a la autobiografía y la memoria; una ética-poética que en cada uno de estos textos configura un espacio de reflexión y crítica sobre la escritura, donde el signo mujer se inscribe como agencia política, de acuerdo con los diferentes modos de producción de la subjetividad/textualidad que promueve el régimen estético de la postautonomía.
\end{abstract}

Palabras clave: Carmen Berenguer, Carmen Ollé, Susana Thénon, escritura de mujeres, subjetividad/textualidad, postautonomía.

Abstract: In this article I propose a reading of three fundamental texts of the 80s-90s
women's Latin-American poetry: Naciste pintada (Carmen Berenguer, 1999), Noches
de adrenalina (Carmen Ollé, 1981), and Ova completa (Susana Thénon, 1987). My
starting point it will be the hypothesis of the differentiated subjectivity by gender
embodiment (women's writing) and a aesthetic-politic of the domestic issues, daily
and micro-political, which in each one of these texts draws a space of deliberation

* Este artículo forma parte del Proyecto FONDECYT de Postdoctorado $\mathrm{N}^{\mathrm{o}} 3130628$ : "Poesía y neovanguardia: textualidades para un nuevo repertorio", del cual soy investigadora responsable. 
and criticism on writing and the ways of generating the subjectivity/textuality that has arisen because of the development of the aesthetic regime of the postautonomy.

Keywords: Carmen Berenguer, Carmen Ollé, Susana Thénon, women's writing, subjectivity/textuality, postautonomy.

Recibido: 15.09.2014. Aceptado: 05.11.2014.

\author{
Al poema le incumbe todo \\ (...) \\ Todo y nada están ahí para ser dichos. \\ El poema es \\ el puente que une dos extremos ignorados. \\ Pero es también esos extremos \\ (Susana Thénon)
}

\section{Para comenzar}

$\mathrm{E}$

S UN CONSENSO DE LA crítica sostener que en el periodo de los 8o latinoamericanos un amplio repertorio de textos escritos por mujeres ha enfatizado y, en algunos casos, exacerbado el gesto vanguardista de translimitar y fusionar los escenarios del arte, la política y la sociedad, bajo la forma de una cita estética neo-experimental y crítica de los bordes-periferias de lo social y cultural (Richard, 1994), como una de las respuestas a la así llamada era del arte poshistórico (Danto, 1999), donde si algo definía lo contemporáneo (o el ser contemporáneo) era la conciencia de que el metarrelato legitimador del arte moderno llegó a su fin. Esa conciencia de ruptura (de lo moderno a lo contemporáneo), avanzada la segunda mitad del siglo $\mathrm{XX}$, aparecería cuando las manifestaciones artísticas perdieron especificidad no solo por la conciencia de la muerte de un metarrelato legitimador del arte $-y$, por extensión, de la literatura-, sino también por la redefinición de la categoría de obra (artística y literaria) que venía sintomatizando la crisis del sistema literario como un campo enunciativo diferenciado de otras prácticas del arte y del saber. Hoy ya no existe más ese linde de la historia, "los artistas se liberaron de la carga de la historia y fueron libres para hacer arte en cualquier sentido que desearan, con cualquier propósito o sin ninguno" (Danto, 1999: 37). 
Este sería el escenario histórico y discursivo para la postautonomía ${ }^{1}$ que Ludmer analiza en la década de los 2000 en Argentina en un corpus de obras narrativas-, como un régimen de "realidadficción" o de "afueradentro", donde "lo" literario va a enfrentar la crisis de su propio metarrelato por la pérdida de su especificidad e impronta crítica, que antaño definiera su estatuto de autonomía en el poder de nombrase y autorreferirse, y cuanto más en el de leerse con este valor de acuerdo con sus posibilidades de cambio, evolución o progreso, siguiendo el supuesto de la superación crítica moderna. Lo que hace este régimen, entonces, es desestabilizar las marcas internas, autorreferenciales, de la norma literaria determinada por los modos narrativos y poéticos de esa esencia signada en el universo de "lo literario"; pero más aún, de borrar los parámetros que definen lo que es literatura, los criterios o las categorías literarias: "todo lo que asegura las identidades literarias, la especificidad y atributos literarios, las marcas de pertenencia a la literatura, a la "literaturalidad" (...) Tanto en sus posiciones como en sus matices, estas escrituras presentan el problema del valor literario” (162).

Entiendo este régimen de la postautonomía como un fenómeno translingüístico que tanto en el orden de lo estético como en el de lo sociocultural, ofrece un replanteamiento de las nociones más tradicionales de literatura y poesía, toda vez que, remitiéndome a los textos del corpus aquí propuesto, frente a la existencia de algo que sería "lo poético" -y los alcances de aquello que, por extensión, sería "lo autónomo"-, algo que podría pensarse como un estándar, modelo, canon o estereotipo, las poetas, Carmen Berenguer, Carmen Ollé y Susana Thénon (y tantas otras), se posicionan en una relación conflictiva con dicho estatuto a la base de una serie de operaciones interdisciplinarias, interartísticas y genéricas, de producción del texto y la subjetividad/textualidad, como un intento por problematizar la agencia de género desde la cual emergen, por un lado, y la herencia o las filiaciones vanguardistas que se traman (conscientemente o no) a nivel simbólico e ideológico en tanto que poética y ética de escritura (relaciones arte-vida, reescritura, técnicas de apropiación como el collage, la cita y el montaje), por otro.

Añade la crítica argentina que en las literaturas postautónomas no se

\footnotetext{
${ }^{1}$ Para una lectura actualizada del concepto de postautonomía, véase Alberto Pucheu (2014).
} 
sabe o no importa si son o no son literatura; y tampoco se sabe o no importa si son realidad o ficción:

Se instalan localmente en una realidad cotidiana para fabricar presente y ese es precisamente su sentido (...) Reformulan la categoría de realidad al atravesar la frontera de la literatura y la ficción: salen de la literatura y entran a la "realidad" y a lo cotidiano, a la realidad de lo cotidiano, y lo cotidiano es la TV y los medios, los blogs, el e-mail, internet. Fabrican presente con la realidad cotidiana y esa es una de sus políticas (151).

Lo que Ludmer (2010) llama "realidadficción” o "afueraadentro" es, por tanto, el espacio-frontera de la política y la representación de la escritura, que en nuestras autoras vuelve a activar el prurito vanguardista de la unión arte-vida. Las poetas reformulan no solo la categoría de realidad, sino también las del circuito crítico de la llamada "poesía escrita por mujeres" a partir de esas condiciones/operaciones de producción del texto y la textualidad, signadas por la agencia de género y la (re)emergencia de la vanguardia; y, ciertamente, entran a la realidad de lo cotidiano, que es todo lo que menciona Ludmer (2010), más la memoria, la biografía, la confesión, lo "referencial", en suma, y la autoimagen que de sí construyen las figuras literarias de la mujer poeta y escritora. Sobra decir, entonces, que los proyectos de obra que éstas nos ofrecen no solo hacen dialogar el texto con los contextos históricos y extraverbales en que se producen, desestabilizando otros sistemas discursivos y reestableciendo los frentes escritura-realidad de la vanguardia histórica, sino que también proponen una subjetividad diferenciada para la comprensión de otras formas del arte y "lo poético" a la base de procedimientos que "retornan" como el poema encontrado, el collage, la ironía y la parodia, para transgredir los márgenes del género (textual y sexual), y hacer de los textos un espacio heterogéneo, de fronteras permeables entre lenguajes, discursos y saberes de distinta naturaleza.

\section{Naciste pintada: Lo cierto es que no podría pintarme de ningún modo}

Si para Carmen Berenguer la poesía es un contra-lenguaje porque no tolera su ejercicio como forma expresivo-creativa de un sujeto heroico, grandilo- 
cuente, intérprete y portador de un sentido de la historia que transmitir o comunicar, la poesía ya no puede ser creación original, directa e inmediata de una voz única e intransferible, cuanto un espacio de desplazamiento y transacción entre el afuera y el adentro de la escritura y la vida. No puede haber más poesía, parece decirnos Berenguer, que aquella encontrada en sus entornos (objetos, lugares, imágenes y discursos) más cotidianos. La poesía, por tanto, es un montaje, y desde allí responde a la premisa, en forma de pregunta que T. W. Adorno planteara en $L$ 'art et les arts: “¿Qué hace el montaje, sino perturbar el sentido de las obras de arte por una invasión de fragmentos salidos de la realidad empírica -invasión sustraída a la legislación del sentido-, y a la vez infligir un desmentido al sentido?” (170).

Carmen Berenguer ocupa el montaje como un dispositivo de representación (construcción/composición de la obra) de acuerdo con una particular posición de la poeta (la voz feminizada del texto) dentro del escenario artístico, político y social del Chile dictatorial y postransición; de donde la figura material y simbólica de la casa que es Naciste pintada (1999)² representa, construye y compone, el espacio-frontera de la memoria histórica y cotidiana de este momento particular de la historia nacional. Una memoria donde los objetos, los lugares, los discursos, las personas y las imágenes de la cultura y la sociedad de la que se es parte como individuo político, pondrán a la poesía en ese lugar impuro donde no puede serlo sino a condición de su carácter exteriorista ${ }^{3}$.

Desde esta trinchera, la del montaje y la poesía impura, Berenguer sostiene la convicción de que todo texto como objeto cultural es, potencialmente, literatura (o al menos soporta el membrete de lo literario), hallándose en cualquier parte y garantizando que en ella todo puede decirse. Como Bataille, ve en la literatura un espacio de transgresión privilegiado, capaz

${ }^{2}$ Otros títulos en poesía de Carmen Berenguer, son: Bobby Sands desfallece en el muro (1983), Huellas de siglo (1986), A media asta (1988), Sayas de pieles (1993), La gran hablada (2002), Mama Marx (2009), Maravillas pulgares (2009/2012) y Venid a verme ahora (2012).

${ }^{3}$ Para Ernesto Cardenal, poesía exteriorista es aquella poesía creada con las imágenes del mundo exterior, el mundo que vemos y palpamos: "es la poesía objetiva: narrativa, anecdótica, hecha con elementos de la vida real, y con cosas concretas, con los nombres propios y detalles precisos, y datos exactos, y cifras y hechos y dichos. En fin, es la poesía impura" (cit. en Higgins, 1993: 194). 
de cruzar todos los límites. Aunque también, si cabe hablar de "discurso poético", haya que considerar la advertencia de Foucault cuando sostiene que: "se sabe bien que no se tiene derecho a decir todo, que no se puede hablar de todo en cualquier circunstancia, que cualquiera, en fin, no puede hablar de lo que sea" (1992: 11). Lo cierto es que bajo esta premisa la autora lleva hasta su extremo el principio de un arte poshistórico, donde el linde de la historia y del arte con sus relatos legitimadores ha llegado a su fin.

Los materiales que utiliza para la construcción/composición de Naciste pintada son objetos, en su mayoría, "encontrados" en la cultura, la ciudad y sus entornos cotidianos, en sus textos e imágenes, que incorpora como desechos o residuos culturales según la técnica del montaje, donde lo fragmentario y la especial atención a la presentación visual del libro como objeto son determinantes; del mismo modo como el uso del ready-made u objet trouvé 4 : desde citas de poemas de distintos autores, letras de canciones, boleros y tangos, entrevistas, crónicas, recortes de titulares y noticias del periódico La cuarta, fotografías de la casa de la tortura en Borgoño 1470, hasta cartas de la prisión que recrean la experiencia de mujeres presas políticas, torturadas durante la dictadura militar.

Para la crítica literaria de los 8o, el montaje de textos aparece como la actividad productora de sentido y cohesión en torno al concepto de subjetividad (Mallol, 2003), donde unas poéticas de lo mínimo, "del destrozo, del trozo y la traza", de lo fragmentario y residual que se expresan en un "alfabeto de la sobrevivencia" (Richard, 1994), intentan nombrar, aun desde la precariedad y hasta imposibilidad del habla, la violencia material y simbólica del horror y la catástrofe que este momento significa. Es allí donde el montaje -como la alegoría - intenta responder a la pregunta: ¿cómo mirar el desquiciamiento de lo real? Pregunta que permite entender el dispositivo del montaje como una forma de comprensión y de exposición de las rui-

${ }^{4}$ En la neovanguardia, el montaje asumiría como el nuevo estatuto de la obra de arte: "el objeto que no es resultado del proceso individual de producción, sino un hallazgo azaroso en el que se materializa la intención vanguardista de unir el arte y la praxis cotidiana, es lo que se reconoce hoy como obra de arte" (Bürger, 1987: 82). Esto es el collage como paradigma de un arte poshistórico, en la comprensión de Danto; o el retorno del ready-made en la de Foster (2001). 
nas y deshechos de la historia; un método, en este sentido, de construcción que el artista emplea, como ingeniero, "para levantar, con esas ruinas de la historia, un 'armazón' filosófico para preparar el 'despertar histórico' que es en Benjamin la acción política” (García, 2010: 160).

El montaje o pegoteo de textos por donde se mira (y cuestiona) este "desquiciamiento de lo real", une la historia individual con la historia colectiva en Naciste pintada, remitiendo a una serie de discursos y lenguajes, propios y ajenos, como la única marca de un resto de subjetividad desde donde recomponer esas ruinas de la historia. Así se deja ver/leer en la "pinturita” de Juan Dávila que aparece al comienzo de la Casa de la poesía por medio de la cita intertextual y la écfrasis:

Juan D registraba todo recopiando estas imágenes, recoloreando esos rostros mestizos, dibujando inteligibles nuestros ojos achinados. Ojos chinescos como cúpulas orientales. Juan Dávila recopiaba unos pómulos altos engastados como planicies cóncavas, poniéndole un color cetrino, aceitunado, un negro descolorado antes de la oscuridad (...). Le puso mis senos al prócer porque esa noche yo era la única que tenía tetas, y le agregó un sexo al héroe del sueño latinoamericano. Al lado le hizo un hoyito, un huequito con su mano, un guiño a nuestros escépticos sueños

(...)

En ese juego de espejos Juan D buscaba un destino mestizo, un destino chinesco, una mezcla criolla. Y encontró en mi boca el lagar salobre de la machi. En las dos bocas provocó la ruptura: vacío de mil bocas repentinas. Y las repintó como granas carcajadas sin poder dramatizar aquel momento que por entremedio de las comisuras, escurría toda la risa inquilina de los dominados que vuelven la boca profanada de Simón Bolívar al primer mundo su propia postal: su retocada.

Esa noche fue simulacro del ritual pagano de la diversión alegre de la chilenidad. Esa noche fue el carnaval andino y sentido, dejando atrás la clásica y profana noche de Velásquez.

Juan Dávila firmó esta pinturita (49). 
En esta "retocada" de la tarjeta postal del "Bolívar travesti" de Juan Dávila $(1994)^{5}$, la poeta opera por "variación" la reescritura de la imagen oficial, heroica y luctuosa, del prócer latinoamericano. Recordemos que a la figura estándar y modélica, Dávila oponía la irreverencia de los gestos y la figura travestida de su cuerpo, generando una provocativa imagen de ambigüedad sexual. Mientras que Berenguer agregaba la condición mestiza del territorio y habitante chilenos -(cumpliendo con ello el objetivo de la tarjeta postal, cual era, según Dávila, la de ofrecer una reflexión sobre la identidad latinoamericana, más que burlar o ridiculizar la figura de Bolívar)-, junto a la autorreferencia que hace corresponder el trazo del pintor con las características físicas del sujeto femenino (feminizado) representado en la china y en el rostro-cuerpo de la poeta que en ella se reconoce o con la cual se autoidentifica. En otras palabras, si ya en el cuadro de Dávila la figura de Bolívar es contrariada, contrapuesta o revertida, en Berenguer es re-escenificada por el collage textual, ecfrástico, que hace del collage pictórico, visual, de Dávila, una lectura que vuelve a modificar una versión ya trabajada respecto de su modelo original. El texto se monta, así, como un collage desjerarquizado de voces, que supone un espacio de codificación abierto al buscar sus posibilidades de expresión verbal en un objeto artístico, como en los objetos del mundo real, las circunstancias históricas y sociales del país (dictadura militar, transición a la democracia), tanto como en la experiencia de vida, individual y colectiva, de un sujeto poético femenino múltiple: mujer, poeta, prostituta, presa política; de donde la oscilación postautónoma del texto entre lo poético, lo cronístico y lo testimonial (todo ello bajo el prisma de lo visual), y dentro de cada uno de estos registros-fragmentos de vida individual y colectiva, entre los biografemas ${ }^{6}$ mínimos de la poeta-narradora Carmen Berenguer y de Brenda, su personaje literario de la Casa de la poesía.

${ }^{5}$ La postal había formado parte de una obra de Dávila exhibida en la Hayward Gallery de Londres, y de un Proyecto del Fondo para la Cultura y las Artes de Chile, Fondart, realizado en conjunto con algunos de los miembros de la llamada Escuela de Santiago: Arturo Duclós, Gonzalo Díaz y Eugenio Dittborn.

${ }^{6}$ Uso biografema en el sentido de Barthes (1971) como recorte, síntesis, reducción; la vida del sujeto representada en un conjunto deliberado de fragmentos, tan significativos que son capaces de trascender su propia materialidad y tiempo de vida. 
Naciste pintada puede leerse, así, a nivel de unidad o conjunto, como un poemario cronístico, de la mirada cotidiana o en el que "se cuenta lo que se vive", en relación con una diversidad de "relatos impresionistas" que interpelan a la memoria histórica y personal mediante sus múltiples "metáforas caseras". Así leemos en el paratexto de Deleuze (1989): "A nosotros nos parece que nunca habría existido el más mínimo Goulag, si las víctimas hubiesen tenido el discurso que tienen hoy los que lloran sobre ellas" (37), el trabajo de la memoria que se urde en clave histórica y personal:

Dos enes ocuparon mi ciudad sitiada. N.N. fue escrito en el patio México del Cementerio general. N.N. fueron las bolsas de plástico en el fondo del mar Pacífico. N.N fue la mujer ensacada del norte. N.N. diseminado en la torre de alta tensión [...] N.N. tuvo la familia chilena. N.N se borró en el registro civil. N.N. se quemó en la ley. N.N. fue el prisionero de mi memoria. N.N. fue el simulacro de tu nombre verdadero. N.N. te hizo irreal. Una investidura de cal ha engastado tu nombre (37).

La Casa: el gran (macro)rrelato nacional de una nación resquebrajada por la impronta de una sucesión de tragedias históricas, desde el "descubrimiento y conquista" hasta la dictadura militar, el retorno a la democracia y la postransición; al que se montan, yuxtapuesto e imbricados, los microrrelatos y las microtragedias del sujeto mujer (poeta, prostituta, presa política) que ha padecido esas grandes tragedias en ese cauce fluyente, donde lo mínimo o lo "menor" se conecta con lo colectivo. La casa es, entonces, otra vez, un espacio intersticial donde se cruzan lo privado y lo público, lo individual y comunitario; un espacio-morada del recuerdo y la cotidianeidad donde se padece y se sufre por desigualdad social, exclusión, discriminación, racismo, por la violencia de la propia historia que se impone como mandato (colonialismo, subalternidad). Un espacio literario, también, que explora la espacialización de las relaciones de poder entre los géneros sexuales y del discurso; allí donde el recado, el relato oral y la narración breve, ocupan el registro de lo poético-testimonial para articular una casa anómala y en fuga respecto de los poderes hegemónicos y las representaciones "autorizadas" del saber/poder.

En la Casa de la poesía, el recorrido de la hablante se sitúa en Valparaíso, lugar en que deambula por sus cerros, el puerto lupanar, y en el que entra en contacto con el mundo del prostíbulo a través del relato de Brenda 
("Sobre su ausencia en los motivos nacionales" y "Sobre sus motivos íntimos"). Esta mujer es otra de las vértebras rotas de la historia, pero también el puente-bisagra que permite cuestionar "lo contemporáneo" desde el pasado-presente que se urde sobre la trama simbólica de la memoria histórica y las microtragedias de la cotidianeidad sin resguardo de sus hablantes. El relato de Brenda activa la posibilidad de narrar la historia por las grietas de lo menor, lo mínimo, lo precario:

Estamos en el barrio chino, en un bar espeso de humo y de sudor. Y en un fragmento de la novela criolla chilena, fuimos invitados a conocer la casa de Brenda, una mujer popular que se ganaba el pan con lo único que tenía: su cuerpo. Respondiendo al desafío de la suerte de ese inolvidable pasaje del lugar sin límites de la novela chilena, donde ronda el misterio de una historia profanada por el atavismo cultural de la época terrateniente en los tugurios del sur. Ya describí su casa en la que hay una fiesta constante, un baile infinito/una música sentimental/una ropa de segunda/unos colores puros/una copia de nada/sin apariencias/una forma de hablar llano sin dobles intenciones/tan de verdad que parece mentira/tan de mal gusto que atrapa/con tanto olor que enciende/tan violento que asusta (59).

Valparaíso, la gran casa-ciudad de la poesía chilena se construye desde el travestismo de las voces de los "lupanares migratorios"; esas voces que van parodiando, en sus recorridos y tránsitos urbanos, distintos discursos de la identidad nacional y de género. Porque el lenguaje, aquí, crea un espacio y con él un cuerpo y una subjetividad (visual, lingüística), que desarma los centros de poder simbólico desde donde se articula lo nacional, llámese la chilenidad, la feminidad, lo occidental (Sierra, 2013). Tratándose de un espacio-cuerpo (el de la prostituta Brenda y sus "motivos íntimos y nacionales"), en cuya voz y figura se imbrican las de la poeta, narradora y cronista, Carmen Berenguer.

En esta casa hechiza, el personaje de Brenda metaforiza el dicho popular de "nacer pintada", cuando apela a la situación de la mujer que nace marcada por un sino adverso de tipo social, pero que expande sus resonancias a todo individuo apresado por un cierto determinismo (Espinosa, 200o). Porque a Brenda no la hizo el destino, sino el ojo colonial que la mira en el barro: 
No olvidemos que ella no usa espejo. Brenda se mira en los charcos (...) allí vio su primera imagen (...). El charco y Brenda hacen el retrato del barrio. No olvidemos que en el barrio no urbanizado, después del temporal áspero de la pobreza, el aguacero hace el barrial. Y apenas titubea un rayo que entibia los corazones, el charco continúa ruin y noble dibujando la sombra de una mujer (...).

-Ese espejo me enseñó a despreciar; haciendo ondear la carcajada del barrio reí de mí misma. Por ese espejo mugroso se paseaba la Cruz del Sur. Por esas aguas marronas individualicé el lucero de la tarde. Por esa inocentona mirada despejaba el romanticismo de una nostalgia porteña -.

-Cuando hablan de arte está ese espejo señalándome su estética. Tal charco latino platica y murmura orfandad en tal sabiduría. Ese charco hizo su escuela en mi cabeza y pobló la incoherencia de sus calles. Me vi buenamoza dando tumbos por los obstáculos de mi ceguera, devolviendo una imagen ondulante después de la lluvia que arrastraba puertas y ventanas cerro abajo - (66-7).

De este modo, entre la visualidad/espacialidad de estas casas de historia y de lenguaje (Casa cotidiana, Casa de la poesía y Casa inmóvil), la voz y las voces de un colectivo femenino yo-nosotras-ellas se desplaza de un lugar a otro (de Santiago a Valparaíso), para documentar y transformar lo real (la pregunta por cómo mirar el "desquiciamiento de lo real”) en un registro paródico y carnavalesco de una casa-ciudad que es tanto física como inventada, hechiza, espectacular.

\section{Noches de adrenalina: a solas gozadora del llanto en el espejo del wc}

Uno de los libros más emblemáticos de la escena literaria de los 80 peruanos es Noches de adrenalina (2005 [1981]), de Carmen Ollé7. Un texto que podemos leer en clave autobiográfica y psicoanalítica como parte de

${ }^{7}$ El otro texto en poesía de Carmen Ollé es Todo orgullo humea la noche (1988); mientras que en narrativa se cuentan: Por qué hacen tanto ruido (1992), Las dos caras del deseo (1994), Pista falsa (1994), Una muchacha bajo su paraguas (2002) y Retrato de mujer sin familia ante una copa (2007). 
las "poéticas emergentes" que, dentro del repertorio textual de la poesía escrita por mujeres en este periodo, pasó a ocupar un lugar central y, a la fecha, ampliamente reconocido y valorado por la crítica.

Sostengo que la obra de esta poeta se inserta dentro de un espacio discursivo en el que el yo que escribe (y suscribe una marca de género) determina la aparición de un "sujeto de la pulsión" (autoerotismo) en contraste con un "sujeto de la palabra" (autobiografía, memoria, diario íntimo), determinante para la autopercepción del cuerpo orgánico como fetiche, así como de la lectura como un proceso indisociable del cuerpo deseante de la escritura; allí donde las relaciones con las partes del cuerpo no son "teológicas", sino "frustraciones, derivadas del dolor de un cuerpo fetiche"; y donde la pérdida es la forma existencial y poética del extravío: "hoy perdí un diente (y hoy perdí un diente)/Me extravío" (19).

Estas relaciones con las partes del cuerpo son las que permiten desocultar la obscenidad del mismo como el proceso de una "doble focalización del habla", valga decir, de un yo-mujer que es, al mismo tiempo, un yo-objeto "que se ve en tanto que visto por los ojos de los otros" (Borsò, 1998: 210); pero, al mismo tiempo, son la constatación de que ese extravío ("impotencia de ligar con el texto”), es el primer síntoma de un sujeto melancólico que siente inhibición ante el deseo sexual y el acto creativo ("práctica erótica mutilada"); tratándose, si acaso, de una patología que hace emerger la actitud narcisista de desnudamiento y éxtasis del cuerpo, así como la (com)pulsión de mostrar y "decirlo todo" con el lenguaje de una "gramática impura" que la aproxime al deseo ilimitado del cuerpo en la adultez, en ese momento de quiebre entre la "infancia mística" y la "adultez erótica" (Villacorta, 2008), que marcará un periodo de aprendizaje vital cuando la hablante lee a Bataille y logra atenuar, mediante la lectura, la sensación de rabia que experimenta frente al estereotipo de mujer que le han hecho asumir:

Bataille me gusta. Es alguien que uno puede leer.

(...)

nos habla como un hombre que sufre con la carne chamuscada por el deseo que es ilimitado

(...)

en algunas sociedades viriles todo se confabula para que otros hablen de nuestro deseo lo designen 
se retuerzan sobre ese "valor-objeto" y nos definen para siempre inválidas.

(...)

Se crece entre cólera.

(...)

hay para esto masturbaciones secretas que son éxodos

solitarias defenestraciones a la luz de la lámpara (23).

En Noches de adrenalina la anatomía es textualidad (Zapata, 2002) cuando diseña la arquitectura física y verbal de un cuerpo incompleto, "lacerado" o "mutilado"; allí, donde las marcas de una escritura que semiotiza en femenino o, parafraseando a Richard, que se construye de acuerdo con un proceso de feminización de la escritura (aunque válido para todo escritor sin distinción de género), connotan la imagen de la "mutilación erótica" como un síntoma del grito (aunque el grito, nos va a decir la poeta, sea la figura de la timidez), que la mujer escritora va modulando conforme se acentúan los síntomas del deterioro físico, pero, sobremanera, según se sitúa un antes y un después, pasado y presente, que marca la autopercepción del cuerpo y el transcurrir de la vida en él:

Tuve que hablar de la mutilación erótica

Ahora hablo del cuerpo mutilado:

El INNOMBRABLE

(...)

Hoy se pierde un diente mañana un ovario

Hoy no ha de durar más que hoy

O mañana a lo sumo un mes (19-20).

El cuerpo desocultado en Ollé se expresa mediante la conciencia herida de una espacio-temporalidad dialéctica entre el aquí con el allá (ParísLima), que va a distinguir entre un ardor pasado, glorioso, frente al estupor invalidante del presente, la madurez:
Enredada en dos lenguas que poseer
dos ciudades se invierten como
dos torsos imaginarios
una perdida en el ardor de su pasado
otra en el estupor de la madurez (75) 
En esa coyuntura que es en realidad una disyuntiva (trágica), confesará la hablante: "En esta mística de relatar cosas sucias estoy sola y afiebrada" (24), evocando la violencia del sollozo y la protesta muda de los síntomas (neurosis, melancolía), que refrendan la (im)posibilidad de relatar esas cosas sucias del cuerpo en relación con los espacio-tiempos en que la experiencia se ha fragmentado en un duelo originario (el paso de la adolescencia a la adultez).

Por otra parte, también confesará (es predominante en el poemario el tono intimista y confesional), como extrayendo las notas tachadas o eliminadas de su diario íntimo -"elimino de este diario una dulce experiencia" (59)-, que la suciedad ha llegado a ser un capítulo de su existencia:

La suciedad llega a ser el capítulo de mi existencia que resiste a la lucidez del adulto, el momento en que al levantarme la falda sobrevino el castigo el miedo a la soledad resbalar en el sueño de lo imaginado embriagado por sus propios olores (...) lo obsceno sigue siendo para mí una prolongación de la incertidumbre (71).

Suciedad, desnudo, obscenidad, ponen de manifiesto que en la mirada narcisista se articula esa prolongación de la incertidumbre, que puede leerse como la etapa de transición desde la niña-adolescente, que descubre su cuerpo en el tacto vergonzante e interdicto de la masturbación -"después de masturbarme quería llorar de miedo y de vergüenza" (67)-, a la mujer del presente que busca reconocerse en la imagen del cuerpo desnudo de la mujer adulta (una imagen que, por cierto, no le satisface); en un proceso de transición que logra captar el objeto de la fantasía sexual de esta mujer que se autoanaliza mediante la "mística" del cuerpo orgánico y sus fluidos, y que, a la postre, aparece como un compendio atomizado de esa misma experiencia, donde, incluso, un sentimiento como el amor es asimilado o absorbido por ella, vuelto equivalente a la suciedad. El amor, parece decir Ollé, es todo lo que entra y sale del cuerpo, pero también todo lo que activa, en la relación cuerpo-mente, su psicología y funcionamiento integral: 


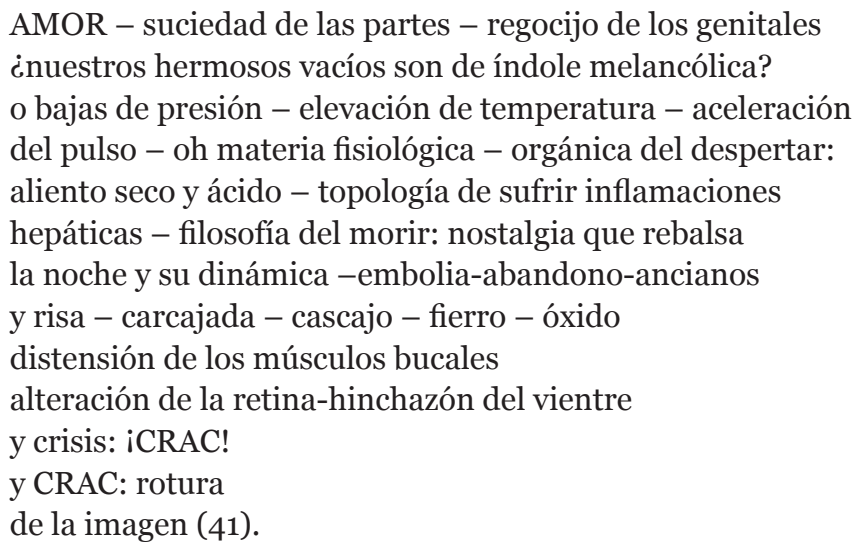

El poema condensa la cruda visión frente a los procesos fisiológicos del cuerpo (heces, orina, menstruación, menopausia) y psicológicos (nervios, melancolía, depresión), que enfrenta la voz poética desde un cuerpo/psicología de mujer, en correspondencia con el proceso psico-auto-analítico de la "transferencia" de los deseos reprimidos; de donde la mascarada de la mujer "teatrera", en su tendencia al fingimiento, verbaliza el acto de lo obsceno (el espejo como objeto simbólico), que también servirá de espéculo a la poeta para ver su otro yo, su "otra mujer" - "abro mi fantasía y la encuentro deliciosa/gozo su cuerpo como otra mujer/esta mujer es mi rival" (62)-. Pero la desnudez en Ollé no es solo un hecho que oblitera el pasado de la infancia-adolescencia en su intento por conjurar el recuerdo de esos años (el paso del ardor al estupor; de la "pulcritud oculta" a la "suciedad jubilosa”), sino también aquello que marca las dificultades del autoconocimiento actual en el presente de la escritura y la práctica del autoanálisis.

En otro pasaje de Noches de adrenalina, la voz poética sostiene una suerte de aforismo-moraleja, que (re)elabora su propia teoría sobre el tópico de la limpieza, prescrita por la higiene:

El que más se lava es el que más apesta como los buenos olores son testimonio de una mala conciencia como el grito es la figura de la timidez (14).

Lo que podemos leer como característica de aquello que W. Rowe (1996) identifica como "el aspecto intelectual" de la escritura de Ollé, a saber, no 
solo la incorporación al texto de citas y referencias literarias de variada procedencia, sino también la continua elaboración de manifestaciones abstractas y analíticas, que actúan como "diagnóstico de las condiciones exploradas y como un cuerpo de pensamiento, un espacio por hacerse" (181). En el ejemplo, la hablante, irónicamente, reflexiona sobre la condición social de la limpieza cuando reconoce que lo suyo ha sido el aprendizaje vital, pero también estético-cultural, de la suciedad; ese aprendizaje que estará siempre en tensión con el orden civilizatorio que establece Freud para la "evolución" de la líbido humana, de acuerdo con las exigencias de "limpieza, orden y belleza" que "ocupan una posición particular entre las exigencias culturales" (1991: 37). Ollé polemiza con el ethos social de la limpieza, que sostiene la sociedad "evolucionada" en sus regímenes de control de las sexualidades, el deseo y el placer, frente a lo obyecto que sitúa el lado puramente instintivo, "bárbaro", de la líbido humana, pero que en Noches de adrenalina sitúa a la suciedad como posibilidad introspectiva de conocimiento y deseo ilimitado del cuerpo en la adultez. Esto es, en otras palabras, la posibilidad de que el cuerpo oculto se abra y se exprese en el lenguaje de lo sucio por intermediación de "las verdades que dice la boca y las que silencian sus partes" (Villacorta, 2008: 117); porque siempre es una boca la que habla, aunque el sonido deje de ser el ruido de un cuerpo como pura oralidad para convertirse en manifestación de un sujeto que se expresa (Deleuze, 1989).

Es esta tensión, finalmente, entre el aprendizaje de la suciedad v/s la limpieza la que activa los signos de la neurosis y las pulsiones narcisistas del sujeto poético de Noches de adrenalina; así lo entiende Villacorta cuando afirma que a partir de la relación limpieza/suciedad se module la identidad de quien habla en sus poemas. Porque en Ollé, palabra y cuerpo se harán uno en esta necesidad exploratoria de liberar el deseo de lo prohibido, pulsión ritual que despliega la posibilidad de anular, en sentido psicoanalítico, el o los "fantasmas" que este yo elucida en su experimentación-conocimiento-aprendizaje del cuerpo y sus partes sucias - "y mis partes están irritadas con fluidos verduscos/como tonos impresionistas" (36)-; cumpliéndose en ello una de las funciones éticas del psicoanálisis, cual es la de conducir al sujeto a que su discurso se acerque al "máximo de excitabilidad, "que la domine y la metabolice" (Kristeva, 1980: 16). Porque 
esta operación, clave para el proceso de hacerse un discurso, un cuerpo de pensamiento, se actualiza en cada cuerpo orgánico en relación con los instintos que le abren camino. Solo de esta forma es posible para el sujeto poético de Ollé construir una subjetividad diferenciada, intimista y fetichista, que limita con los bordes de sus propias contradicciones desplegadas, sus espacios atomizados de perversión, sus grietas adosadas al poder de la palabra que se busca y no se encuentra, al poder deseante de una identidad autoconstruida por lo fluido y el flujo, por la escritura y el propio cuerpo (sus tabúes y clichés):

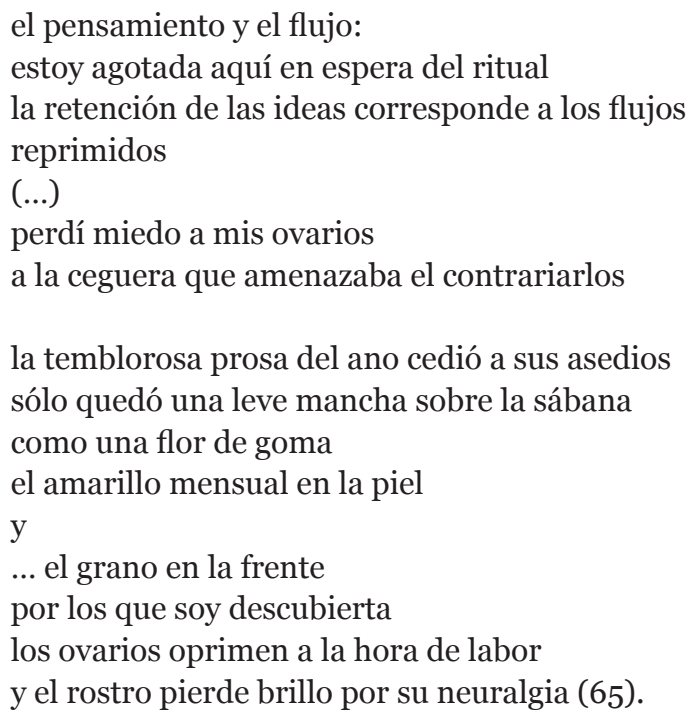

\section{Ova completa: esto no es un poema, es un grito de rabia}

Cuando en uno de los versos de Susana Thénon leo: "Esto no es un poema: Es un grito de rabia”, recuerdo las palabras de Carmen Ollé a propósito de Blanca Varela: si la ironía resulta lacerante es porque existe temor al grito, "temor a que en el lenguaje poético este grito sea panfletario, parodia de un grito" (1998: 188). Y pienso que si es por ese temor que la poeta se autoironiza, resulta comprensible la operación de Thénon por construir en Ova 
completa (2012 [1987] $)^{8}$ un doble ficcional de sí misma que modula la voz en dicciones múltiples, enmascaradas o desdobladas, a fin de construir una voz-posición en tanto que (auto)ironía y (auto)parodia de un sujeto mujer y poeta.

La tendencia "plagiaria" de Thénon por mezclar registros y formas múltiples de habla y discurso, ha sido leída por Susana Reisz como un mero acto de apropiación, carente de compromiso (¿político?), de distanciamiento irónico e, incluso, de renegación de lo injertado o absorbido en esos otros discursos y formas de lenguaje y habla. Pero la misma Reisz reconoce que el plagio como la superchería, la imitación o el fingimiento, pueden tener una función contestataria dentro de un contexto político particular, mas no es forzoso que lo tengan, sosteniendo que en los 80 las escritoras latinoamericanas parecen admitir que como tales no poseen un lenguaje propio y, por lo mismo, la única posibilidad de articular una voz fuera de lo doméstico es el empleo de la cita o la apropiación de las voces del canon dominante, sea literario, estético, filosófico o político. El caso de Thénon parece decidor a este respecto cuando su actividad poética semeja la de un ventrílocuo, una figura de estilo que consiste en deconstruir los discursos hegemónicos por medio de la imitación burlesca y la pseudo-cita, mas sin corresponderse del todo con la orientación ideológica de la parodia. En su escritura, la autora asume la polifonía "plurilingüe y semántica" de un conglomerado de voces ajenas que imitan estilos y formas de habla populares (la murga, el tango, el refrán), con un sentido lúdico y carnavalesco hasta lo grotesco y la caricatura. Recordemos que el ventrílocuo es una figura de estilo que permite oír una lengua marginal, estereotipada y vulgar, pero también una lengua que deforma el lenguaje, comprimiéndolo y dilatándolo, "porque las palabras al salir del ventrílocuo se convierten en una masa de lenguaje incomprensible en su avalancha verbal y donde muchas veces, se dibuja una realidad informe que vale más por el acento, por la inflexión, que por el significado" (Montecino, 1993: 164).

${ }^{8}$ Constituyen la obra poética de Susana Thénon: Edad sin tregua (1958), Habitante de la nada (1959), De lugares extraños (1967), Distancias (1984) y Ova completa (1987). Todos estos más la obra fotográfica, traducciones, ensayos y poemas inéditos, se reúnen en La morada imposible, tomos I y II, a cargo de Ana M. Barrenechea y María Negroni, Buenos Aires: Corregidor, 2001/2012. 
Uno de los textos más radicales en el empleo de esta estrategia es el poema homónimo del libro, "Ova completa”, al comparecer en él no solo la ruptura sintáctica y semántica de múltiples registros de habla, injertos de discursos, discordantes e inarmónicos, que dialogan con el estereotipo bien ponderado de la "obra completa", fórmula editorial que hace de los textos monumentos y piezas de museo, "obra completa acabada, clausurada, intangible, gigante, venerable, momificada en la letra” (Reisz, 1996: 146). Un objeto que, como parte de la tradición cultural y literaria de referencia, tiene por función recopilar la producción de los escritores de manera casi siempre póstuma, a fin de reafirmar su posición dentro del canon. Claramente es contra este modelo, valor y función de la obra completa que reacciona Thénon. El poema y, por extensión, el libro desestabilizan la seguridad que otorgan los monumentos, la tradición, el canon, las costumbres, lo ya dicho en el habla, lo ya escrito en la literatura (Mallol, 2003); proponiéndose, más bien, como un enfrentamiento hacia ese espacio de legitimación del sistema literario, que objeta la idea de consagración autoral y la posibilidad de concebir la obra como totalidad (Gamboa, 2013). Pero, ċcon qué dialoga este estereotipo?, con la expresión latina ova, una pseudo-cita, pseudoerudita que, por si caben dudas en el cuerpo del poema, se aclara fuera del texto en un "discurso complementario", la nota al pie:

OVA: sustantivo plural neutro latino. Literalmente: huevos.

COMPLETA: principio pasivo plural neutro latino en concordancia con huevos. Literalmente colmados. Variantes posibles: rellenos, repletos, rebosantes, henchidos (155).

Lo primero que se advierte es el tono burlesco que desvirtúa la connotación de seriedad o verdad que comúnmente tiene el procedimiento de la nota al pie de página, pues si algo no está claro en el cuerpo del texto, entonces confrontamos la nota, pero no necesariamente cuando leemos poesía. En este caso, la parodia reaparece como prolongación semántica del contenido del poema y de su intención carnavalesca, satírica, de manera tal que no solo repite el gesto, sino que lo satura por efecto de su significado redundante, sobreentendido. Sin embargo, la nota al pie agrega algunas pistas para leer "Ova completa”, el poema y el libro, como un afueraadentro que densifica su marca ideológica. Primero, porque sugiere la relación entre huevos y óvulos y, en tal sentido, cifra el contenido del poema para aler- 
tar que se trata de la escritura de una mujer (he aquí la problematización de la agencia de género), aunque huevos completos, rellenos o rebosantes no sean necesariamente correspondencias o equivalencias de aquello que deforma la expresión "obra completa". Segundo, porque la nota proyecta en el título todas las expresiones cultas, coloquiales, botánicas, zoológicas, gastronómicas, sexuales, corporales o anímicas, que los huevos y su "relleno" pueden sugerir (Reisz, 1996: 147). Para Mallol (2003), esto es el juego de la perífrasis-paráfrasis que enfatiza el "idiotismo" ya conocido del sujeto enunciador de Thénon, sus travestismos, trasposiciones, cambios de género e identidad: "Susana es la que escribe con los huevos hinchados, con las pelotas llenas (...) el disparate, presentado casi como un gesto histriónico" (44).

Y si en la cita, la voz opera el juego paródico de la inversión e imitación satírica a partir de la etimología ova, lo mismo sucede en el cuerpo y centro del poema con las raíces etimológicas de la palabra filosofía:

filosofía significa 'violación de un ser viviente' viene del griego filoso, 'que corta mucho' y fia, $3^{\text {a }}$ persona del verbo fiar, que quiere decir 'confiar' y también 'dar sin cobrar ad referendum' (155).

El poema va ejecutando en forma progresiva la acción del verbo que descompone en su etimología: filosofía como violación de un ser viviente:

Una vez consumada la filosofía

Se hacen presentes por orden de aparición:

La taquería el comisario el juez de la causa

El forense el abogado de oficio el reportero gráfico

(...)

Filosofía significa 'violación de un ser viviente' Cuando tu pena es condonada 36 años después Retomás su ejercicio o te lo ejercen (155-6).

Los personajes que intervienen en el poema hacen un espectáculo de la tragedia que puede significar, en la realidad, la violación de un ser viviente. Lo mismo ocurre en "Murgatorio" (variación del purgatorio dantesco, cristiano) con el refrán "olé olé olé olá yo soy el nieto de mi papá", donde un hecho por demás complejo como el incesto es tratado de forma ramplona 
(aunque, se sabe bien: toda risa esconde un dolor, una herida), eludiendo el tratamiento de una reflexión seria y profunda sobre el tema. Pero más que el purgatorio, lo que en este poema resuena es la figura del averno como un espacio pagano, al tiempo que anodino e impasible desde la perspectiva social y familiar; tratándose de un más acá de la vida (el aquí y ahora) donde a nadie le importa nada... por eso su reino es el vacío o la nada:

olé olé
olé olá
nadie con...............testa en
el más
a
cá (187).

Pero en "Ova completa", los personajes no solo actúan o performan, como las voces del mismo poema, el significado etimológico de la palabra filosofía, sino que además banalizan su sentido al interior del texto, desautorizando su propio sistema discursivo. El filósofo de Thénon tiene por oficio violar y como tal viola; lo que aparece como un hecho punitivo que se condena, pero que no obsta a que el agresor (el filósofo) repita su acción una vez cumplida su condena. De no hacerlo, corre el riesgo de convertirse él mismo en víctima: "Retomás su ejercicio o te lo ejercen". Aquí la acción lingüística señala una forma de violencia y contra-violencia que puede ser tanto física como simbólica, por lo que no solo es parodiada la institución literaria en la inversión de "Obra" por "Ova", sino también otra figura central de la cultura letrada, la filosofía, que lejos está en esta etimología de 'filos', que corta mucho, la de ser una disciplina, un ámbito o dominio del saber que propicia el desarrollo del pensamiento y conocimientos de la humanidad. La ironía funciona, aquí, como una queja dirigida contra la academia, contra los saberes y disciplinas consagrados según los modelos del campo cultural y enunciativo en que se expresan, pero también contra el sistema del lenguaje como un campo de jerarquías, regulaciones y reglamentaciones para decir o modular esos saberes. El poema-libro, claro está, se burla de la alta cultura en general, en circunstancias que su posición ideológica consiste no solo en ironizarla, sino también en desacreditarla en todas las dimensiones y manifestaciones de "lo letrado" o "lo culto" (como ocurre con los discursos de la ciencia, la historia y la literatura), en un sentido que 
va siempre de lo lúdico a lo grotesco, y de los grotesco a lo carnavalesco y caricaturesco. Thénon verbaliza su incomodidad, su grito de rabia que resentía el carácter normativo del campo de la lengua, cuando su "No es un poema" advertía sobre lo que en realidad es: "un puntapié universal/un golpe en el estómago del cielo/una enorme náusea/roja/como era la sangre antes de ser agua" (55). Un grito que en Ova completa desestructura los dispositivos del poder letrado en el uso correcto, formal, institucional de la lengua en sus distintos campos de acción sociocultural, por la denuncia de la violencia simbólica (las más de las veces inconsciente o naturalizada) que esta ejerce sobre los usuarios:

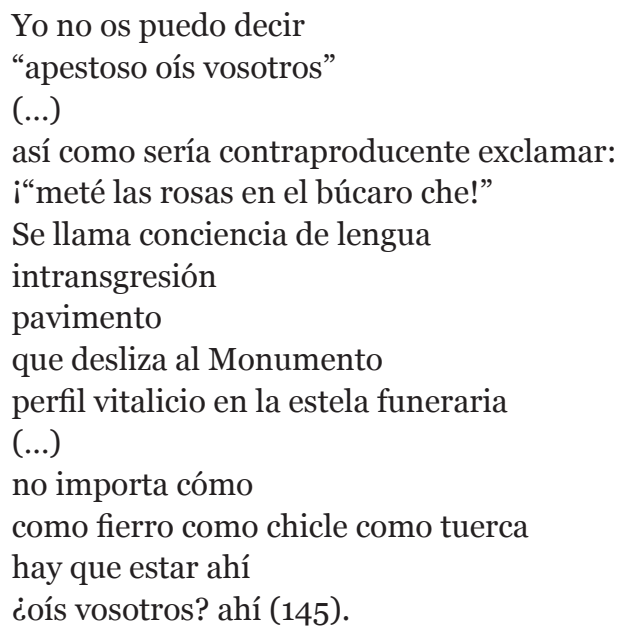

Del mismo modo, el poema "La antología", otra fórmula parodiada de la obra completa, y por extensión de la institución literaria, despliega las mil máscaras de la poeta Susana Thénon por la voz, otra vez, ventrílocua del texto y su tono autoparódico, que presenta la posición/disposición de las protagonistas, Susana Etcétera, la poietisa, y Petrona Smith-Jones, la profesora-investigadora canadiense:

¿tú eres la gran poietisa Susana Etcétera? mucho gusto me llamo Petrona Smith-Jones soy profesora adjunta de la universidad de Poughkeepsie que queda un poquipsi al sur de Vancouver y estoy en argentina becada 


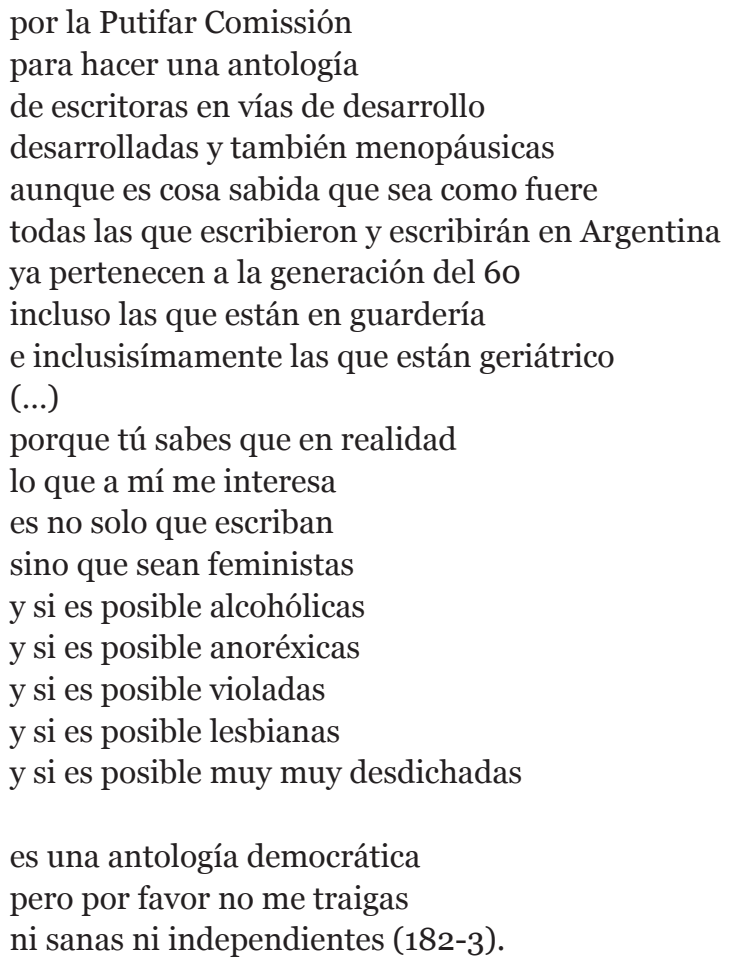

Thénon trabaja aquí sobre el tópico del estereotipo mujer y poeta, pero proclamando un tono de "satisfecho cinismo" en la apelación a "la gran poietisa"; la que solo sabe fingir, reconocerse a sí misma como actriz, cantante de boleros y tangos, ċla poeta Susana Thénon? Al igual que en Ollé, el texto puede leerse en clave autobiográfica. En el juego autoparódico, esta mujer-poeta tiene un nombre pseudo o a medias ficcional, Susana Etcétera, como si el etcétera fuera una prolongación del nombre propio, pero al mismo tiempo la proyección de un nosotras que se hace colectivo en dicha fórmula al expresar continuidad o potencialidad de ser; sugiriendo la idea de que hay o podría haber otras Susanas, grandes poet(is)as.

El poema sitúa una voz, la antologadora, investigadora canadiense, e interpela a un tú implícito pero directo, la poietisa Susana Etcétera, invirtiendo la forma consensuada ("democrática") de aludir a la mujer que escribe poesía en este giro a la griega de poietisa, pues actualmente no existe el distingo de género para el sustantivo poeta. Es decir, la voz actuali- 
za con sentido autoparódico y burlesco la fórmula estereotipada con que antaño se designaba la condición de género de la mujer escritora (con un claro sentido despectivo). No por nada la profesora-investigadora se llama, también, en este juego paródico del nombre propio, Petrona, derivado del latín Petronio, en el remanente que produce la carga simbólica del origen patriarcal y dominante de la estirpe noble de sus antepasados, la familia romana, y de la pertenencia social en el vínculo del matrimonio que señala su doble apellido, Smith-Jones. En este sentido, Thénon se encarga de que todos los estereotipos de género estén presentes en y desde el nombre propio. Pero si la voz está oralizada por medio de este pseudo-diálogo que sostiene la investigadora con la poeta, vemos que nunca se produce un verdadero diálogo o que éste queda trunco en su operación, puesto que aquélla (la poeta) no aparece ni responde a lo largo de todo el poema.

El hilo discursivo del texto sigue el orden del despliegue de los estereotipos que va enunciando la investigadora. Primero, se presenta y, luego, enumera las características que, en realidad, son las condiciones que pone para realizar su antología de poetas mujeres de varias generaciones (en vías de desarrollo, desarrolladas y menopáusicas). El criterio, como se ve, lejos de toda ética profesional, redunda en la erosión del estereotipo de la poeta feminista (que escriba o no es casi accesorio) con cierto aire de malditismo: alcohólica, lesbiana, violada, pero sobre todo desdichada. Esta es la imagen de la poeta (¿las patologías del grito de la mujer?) que se explota frente al público extranjero por su figura excéntrica, antes que por el valor de sus versos o la calidad estética de su escritura; valga decir por el exotismo al que se le obliga proyectar como otredad. Tampoco es casual que la investigadora venga del primer mundo en busca de recursos para explotar la figura significante del sur indómito y salvaje. Lo que bien destaca Gerbaudo (2009) cuando señala que este poema, casi veinte años antes de las demoledoras críticas de Slavoj Zizek a la "agenda multicultural", advierte sobre la superficialidad de la diferencia pensada y tratada, en el contexto de una agenda de investigación literaria, como exotismo. El final del poema termina como una sátira sobre la sátira que invalida, por saturación, el mismo procedimiento satírico: "es una antología democrática", dice, cuando todo principio ético ha sido obliterado ya desde el comienzo del mismo.

Thénon y sus hablantes se mofan, así, de todas las posibles formas correctas, canonizadas, de habla, tanto como de los discursos que emplaza la 
cultura letrada, y de los agentes del capital simbólico que ella promueve y garantiza (poetas, filósofos, académicos, investigadores, entre los principales). Pero la burla se dirige, sobremanera, contra esas formas del "bien decir" dictadas por la norma lingüística para modelar las identidades socioculturales. De allí que, frente a determinadas zonas de sentido homogéneas, la construcción de este collage de voces haga posible discutir y desmontar la idea del lenguaje como un constructo neutro que propicia una comunicación transparente. El sujeto mujer-poeta (o las voces del ventrílocuo de Susana Thénon), oraliza la voz de otro porque no tiene voz propia, y parece no importarle demasiado llegar a tenerla, disgregándose, más bien, en una serie de objetos, voces y situaciones comunicativas (a veces al borde del non sense), que operan como síntoma de su carácter falsario, bufonesco, autoparódico, hipócrita; lo que sintetiza las propiedades-circunstancias de un descentramiento y una ética-política de escritura: el yo anti-creativo o anti-original (que veíamos operar también en Berenguer bajo la forma del montaje y el collage de materiales) como siempre otro(s), antes que la noción/posición de un sujeto creativo, expresivo, unitario y estable.

\section{Para concluir}

En cada uno de los textos a que me he referido descuella el gesto vanguardista tanto de experimentación con la palabra, en el más amplio sentido de cuestionar y desestructurar el género o aquella convención signada en la fórmula de "lo poético" que resume el régimen de la postautonomía, como de acercamiento del arte a la vida (en los tres casos la relación de la escritura con la biografía y la memoria es determinante), conforme una agencia estético-política de mujer, que (se) interroga por las formas de construcción/composición de la identidad individual y colectiva, histórica, nacional y local (Berenguer); que formula un autoanálisis (verbal y físico) en el presente de la escritura para explorar las vicisitudes del deseo, el placer y sus goces, siempre interrumpidos o inacabados por los complejos y patologías de un sujeto narcisista (Ollé); o que se autoparodia en el uso autoconsciente de múltiples voces donde se oyen (con todas sus resonancias culturales) los estereotipos de género (Thénon) que operan en todos los estratos y dimensiones de la vida social. 
Así, como un espacio de reflexión y crítica sobre la escritura y sus modos de producción de una subjetividad de mujer, cotidiana y micropolítica, la pluralidad y heterogeneidad discursiva que desarrollan estas poetas en el marco de una escritura "feminizada" antes que solo "de mujer", permea el uso de la postautonomía como ese afueraadentro de la escritura y la vida, donde operaciones como el collage y el montaje textual (Naciste Pintada), los registros "referenciales" de la escritura como la autobiografía y la memoria (Noches de adrenalina) y el empleo de la parodia y lo carnavalesco (Ova completa), determinan los ejes (neo)vanguardistas de unas poéticas de lo íntimo y lo doméstico, donde el fragmento, el corte y el recorte, es la textura de las voces y las miradas que se urden en su trama simbólica al filo de las demarcaciones del poder (de la palabra y la lengua, de quién tiene derecho a decir qué).

\section{Referencias}

Adorno, T. W. (2002 [1967]). L'Art et les arts. Trad. J. Lauxerois y P. Szondy. París: Desclée de Brouwer.

Barthes, R. (1971). Sade, Fourier, Loyola. París: Du Seuil.

Berenguer, C. (1999). Naciste pintada. Santiago de Chile: Cuarto Propio.

Borsò, V. (1998). La poesía del eco en la escritura de los años 80: Blanca Varela, Giovanna Pollarolo y Carmen Ollé. En Kohut, K.; Morales Saravia, J. y Rose, S. (eds.), Literatura peruana hoy: crisis y creación (pp. 196-217). Frankfurt/Main: Vervuert.

Bürger, P. (1987). Teoría de la vanguardia. Barcelona: Península.

Danto, A. (1999). Después del fin del arte. Barcelona: Paidós.

Deleuze, G. (1989). Lógica del sentido. Barcelona: Paidós.

Espinosa, P. (2000). Intimidad maldita. Rocinante, 18, 3.

Foster, H. (2001). El retorno de lo real. La vanguardia a finales de siglo. Madrid: Akal.

Foucault, M. (1992). El orden del discurso. Madrid: Tusquets.

Freud, S. (1991). El malestar en la cultura. Madrid: Alianza.

Gamboa, J. (2013) Los márgenes de la lírica. Ironía y subversión poética en Susana Thénon y Roque Dalton. Tesis de Maestría, Facultad de Filosofía y Letras, Universidad Nacional Autónoma de México.

García, L. I. (2010). Alegoría y montaje: El trabajo del fragmento en Walter Benjamin. Constelaciones. Revista de teoría crítica, 2, 158-185.

Gerbaudo, A. (2009). Corta pero no mala: Notas sobre literatura argentina. 
Boletim de Pesquisa Nelic, 2, 24-41 Disponible en: file://D:/Marcelo/ Downloads/11084-33690-1-PB.pdf

Higgins, J. (1993). Hitos de la poesía peruana. Lima: Milla Batres.

Kristeva, J. (1980). Poderes de la perversión. Buenos Aires: Siglo XXI.

Ludmer, Josefina. (2010). Aquí América Latina, una especulación. Buenos Aires: Eterna Cadencia.

Mallol, A. (2003). El poema y su doble. Buenos Aires: Simurg.

Montecino, S. (1993). Sangres cruzadas: mujeres chilenas y mestizaje. Santiago de Chile: SERNAM.

Ollé, C. (1998). Poetas peruanas: ¿es lacerante la ironía? En Kohut, K.; Morales Saravia, J. y Rose, S: (eds.), Literatura peruana hoy: Crisis y creación (pp: 187-195). Frankfurt/Main: Vervuert. (2005 [1981]). Noches de adrenalina. Lima: Flora Tristán-Lluvia Editores.

Pucheu, A. (2014). La apoesía contemporánea: a partir de los conceptos de postautonomía e imaginación pública de Josefina Ludmer. Cuadernos de Literatura, 35, 211-224.

Reisz, S. (1996). Voces sexuadas. Género y poesía en Hispanoamérica. Lleida: Asociación Española de Estudios Literarios Hispanoamericanos.

Richard, N. (1994). La insubordinación de los signos: (cambio político, transformaciones culturales y poéticas de la crisis). Santiago de Chile: Cuarto Propio.

Rowe, W. (1996). Hacia una poética radical. Ensayos de hermenéutica cultural. Rosario-Lima: Beatriz Viterbo-Mosca Azul Editores.

Sierra, M. (2013). Los devenires urbanos de Carmen Berenguer. En Magda Sepúlveda (ed.), Chile urbano: La ciudad en la literatura y el cine (pp. 167186). Santiago de Chile: Cuarto Propio.

Thénon, S. (2012 [1987]). Ova completa. Buenos aires: Corregidor.

Villacorta, C. (2008). Erotismo y espacio en Noches de adrenalina de Carmen Ollé: una lectura de Bataille y Bachelard. INTI, 67-68, 117-126.

Zapata, M. Á. (2002). Anatomía y textualidad en la poesía de Carmen Ollé. En Moradas de la voz. Notas sobre la poesía hispanoamericana contemporánea (pp. 105-120) Lima: Universidad Nacional Mayor de San Marcos. 